\title{
Profil hasil pemeriksaan foto toraks pada pasien pneumotoraks di Bagian / SMF Radiologi FK Unsrat RSUP Prof. Dr. R. D. Kandou Manado periode Januari 2015 - Agustus 2016
}

\author{
${ }^{1}$ Windy D. P. Masengi \\ ${ }^{2}$ Elvie Loho \\ ${ }^{2}$ Vonny Tubagus
}

\author{
${ }^{1}$ Kandidat Skripsi Fakultas Kedokteran Universitas Sam Ratulangi Manado \\ ${ }^{2}$ Bagian/SMF Radiologi Fakultas Kedokteran Universitas Sam Ratulangi Manado \\ Email: windy.mas3ngi@gmail.com
}

\begin{abstract}
Radiology examination especially chest $\mathrm{x}$-ray can enforce various kinds of pulmonary diseases inter alia pneumothorax. Pneumothorax is defined as the presence of air in the pleural cavity. The causes of pneumothorax are very diverse ranging from idiopathic, infection, trauma, and iatrogenic. This study was aimed to obtain the profile of chest x-ray in patients with pneumothorax. This was a retrospective descriptive study by using secondary data from the medical records at the Department of Radiology Prof. Dr. R. D. Kandou Hospital Manado from January 2015 to August 2016. Samples were the medical records of patients that were radiologically diagnosed as pneumothorax. There were 41 patients that were diagnosed radiologically as pneumothorax. The majority of cases were male (90.2\%), age group $>50$ years $(36.6 \%)$, location of lesion in the right hemithorax $(53.7 \%)$, and secondary spontaneous pneumothorax as the etiology (43,9\%). Conclusion: In this study, pneumothorax was more common among males, age group of $\geq 50$ years, and secondary spontaneous pneumothorax as the etiology of pneumothorax.
\end{abstract}

Keywords: pneumothorax, radiology, chest x-ray

\begin{abstract}
Abstrak: Pemeriksaan radiologi khususnya foto toraks dapat menegakkan berbagai macam diagnosis penyakit paru, salah satunya ialah pneumotoraks. Pneumotoraks adalah terdapatnya udara bebas didalam rongga pleura dengan penyebab yang sangat beragam mulai dari idiopatik, infeksi, trauma, maupun iatrogenik. Penelitian ini bertujuan untuk mengetahui profil hasil pemeriksaan foto toraks pada pasien pneumotoraks. Jenis penelitian ialah deskriptif retrospektif dengan pengambilan data di Bagian Radiologi RSUP Prof. Dr. R. D. Kandou Manado pada bulan Januari 2015 sampai dengan Agustus 2016. Sampel yaitu data rekam medik pasien yang didiagnosis pneumotoraks secara radiologis sebanyak 41 pasien. Yang tersering ditemukan ialah pasien laki-laki sebanyak 37 orang $(90,2 \%)$, kelompok usia $>50$ tahun sebanyak 15 orang $(36,6 \%)$, lokasi lesi hemitoraks deksra sebanyak 22 kasus $(53,7 \%)$, serta etiologi pneumotoraks spontan sekunder sebanyak 18 kasus $(43,9 \%)$. Simpulan: Pada penelitian ini didapatkan pneumotoraks paling banyak pada laki-laki, kelompok usia $\geq 50$ tahun, dengan pneumotoraks spontan sekunder sebagai etiologi tersering.

Kata kunci: pneumotoraks, radiologi, foto toraks
\end{abstract}

Pernapasan merupakan salah satu sistem organ terpenting yang khususnya melibatkan paru-paru sehingga bila terjadi gangguan pernapasan dapat mengakibatkan gawat napas. Peningkatan penyakit pernapasan beberapa tahun terakhir terus meningkat dengan berbagai penyebab, dan yang paling banyak terjadi yakni trauma 
dan infeksi. Salah satu penyakit saluran pernapasan ialah pneumotoraks yang bisa disebabkan oleh trauma maupun infeksi. Pneumotoraks merupakan keadaan darurat yang harus segera cepat tertangani. ${ }^{1}$

Pneumotoraks adalah kondisi adanya udara di rongga pleura. ${ }^{2}$ Kondisi ini merupakan gangguan pernapasan yang relatif umum dan dapat terjadi dalam berbagai penyakit dan pada individu dari segala usia. ${ }^{3}$ Pneumotoraks ditandai dengan dispnea dan nyeri dada yang berasal dari paru-paru maupun dinding dada yang disebabkan oleh adanya udara pada rongga pleura yang diikuti pecahnya bula. ${ }^{4}$ Klasifikasi pneumotoraks berdasarkan penyebab dan gejalaklinis yang timbul. Pneumotoraks dapat dibagi menjadi spontan primer (PSP) dan sekunder (PSS), serta traumatik dan iatrogenik. ${ }^{5}$

Insiden pneumotoraks pada laki-laki lebih banyak dari pada perempuan $(5: 1)^{6}$ Kasus PSP di Amerika 7,4/100.000 per tahun untuk laki-laki dan 1,2/100.000 per tahun untuk perempuan sedangkan insiden PSS dilaporkan 6,3/100.000 untuk laki-laki dan 2/100.000 untuk perempuan. ${ }^{7}$ PSS yang paling sering terjadi yaitu pada PPOK sedangkan penelitian oleh Myers melaporkan bahwa tuberkulosis selalu menunjukkan terjadinya pneumotoraks. $^{8}$ Penelitian Weissberg ${ }^{9}$ terhadap 1.199 pasien pneumotoraks mengenai insiden beberapa jenis pneumotoraks mendapatkan 218 pasien PSP, 505 PSS, 403 pneumotoraks traumatik, dan 73 pneumotoraks iatrogenik. Untuk letak lesi pneumotoraks, lesi kanan lebih banyak ditemukan dibandingkan lesi kiri ${ }^{10}$ sedangkan pada penelitian Sadikot ${ }^{11}$ didapatkan letak lesi kiri lebih banyak ditemukan.

Suatu penyakit paru belum dapat disingkirkan dengan pasti sebelum dilakukan pemeriksaan radiologik, ${ }^{12}$ khususnya foto toraks yang dapat membantu dalam menegakkan diagnosis pneumotoraks. $^{12,13}$

Penelitian ini bertujuan untuk mendapatkan profil hasil pemeriksaan foto toraks pada pasien pneumotoraks di Bagian Radiologi/SMF FK Unsrat RSUP Prof. Dr.
R. D. Kandou Manado periode Januari 2015 - Agustus 2016.

\section{METODE PENELITIAN}

Jenis penelitian ini ialah deskriptif retrospektif dengan memanfaatkan data sekunder berupa catatan medik di Bagian Radiologi FK Unsrat/SMF RSUP Prof. Dr. R. D. Kandou Manado. Penelitian dilaksanakan pada bulan Oktober - November 2016.

Populasi penelitian ialah semua data rekam medik pasien pneumotoraks yang terdiagnosis klinis dan melakukan pemeriksaan foto toraks di Bagian Radiologi RSUP Prof. Dr. R. D. Kandou Manado periode Januari 2015 - Agustus 2016. Sampel penelitian ialah semua data rekam medik pasien pneumotoraks yang terdiagnosis klinis dan yang sudah terdiagnosis secara radiologis.

Kriteria inklusi yaitu pasien dengan klinis pneumotoraks dengan data berupa umur, jenis kelamin, dan mempunyai hasil ekspertisi foto toraks berisi lokasi lesi hemitoraks sedangkan kriteria eksklusi yaitu semua data rekam medik yang tidak lengkap. Variabel penelitian ialah distribusi jenis kelamin, kelompok usia, lokasi lesi hemitoraks, dan etiologi pada pasien dengan diagnosis radiologis pneumotoraks.

Data diolah berdasarkan variabel penelitian dengan menggunakan SPSS, disajikan dalam bentuk teks dan tabel, serta dianalisis.

\section{HASIL PENELITIAN}

Hasil penelitian mendapatkan 83 pasien dengan diagnosis klinis pneumotoraks dan yang terdiagnosis secara radiologik yaitu 41 pasien. Berdasarkan data dari 41 pasien pneumotoraks, didapatkan bahwa pneumotoraks paling banyak diderita oleh laki-laki berjumlah 37 pasien $(90,2 \%)$ sedangkan pada perempuan berjumlah 4 pasien $(9,8 \%)$ (Tabel 1).

Kasus pneumotoraks terbanyak ditemukan pada kelompok usia $\geq 50$ tahun yaitu 15 pasien $(36,6 \%)$, dan yang paling sedikit yakni pada kelompok usia 10-19 tahun yakni 3 pasien $(7,3 \%)$ (Tabel 2$)$. 
Tabel 1. Distribusi pasien pneumotoraks berdasarkan jenis kelamin

\begin{tabular}{ccc}
\hline Jenis kelamin & n & \% \\
\hline Laki-laki & 37 & 90,2 \\
Perempuan & 4 & 9,8 \\
Total & 41 & 100,0 \\
\hline
\end{tabular}

Tabel 2. Distribusi pasien pneumotoraks berdasarkan kelompok usia

\begin{tabular}{ccc}
\hline $\begin{array}{c}\text { Kelompok usia } \\
\text { (tahun) }\end{array}$ & n & \% \\
\hline $10-19$ & 3 & 7,3 \\
$20-29$ & 10 & 24,4 \\
$30-39$ & 8 & 19,5 \\
$40-49$ & 5 & 12,2 \\
$\geq 50$ & 15 & 36,6 \\
Total & 41 & 100,0 \\
\hline
\end{tabular}

Berdasarkan gambaran foto toraks pasien pneumotoraks ditemukan lesi pada hemitoraks kanan lebih banyak yaitu 22 pasien $(53,7 \%)$ dibandingkan lesi pada hemitoraks kiri yaitu 19 (46,3\%) (Tabel 3).

Tabel 3. Distribusi pasien pneumotoraks berdasarkan lokasi lesi hemitoraks

\begin{tabular}{ccc}
\hline Lokasi hemitoraks & n & \% \\
\hline Kanan & 22 & 53,7 \\
Kiri & 19 & 46,3 \\
Total & 41 & 100,0 \\
\hline
\end{tabular}

Etiologi yang didapat dari 41 pasien pneumotoraks yang terdiagnosis klinis dan radiologis terbagi atas spontan primer, spontan sekunder, dan traumatik (Tabel 4).

Tabel 4. Distribusi pasien pneumotoraks berdasarkan kelompok umur

\begin{tabular}{ccc}
\hline Etiologi & n & \% \\
\hline Spontan primer & 7 & 17,1 \\
Spontan sekunder & 18 & 43,9 \\
Traumatik & 16 & 39,0 \\
Total & 41 & 100,0 \\
\hline
\end{tabular}

Dari 41 pasien dalam penelitian ini, etiologi yang tersering yaitu PSS sebanyak 18 pasien $(43,9 \%)$. Pada pneumotoraks traumatik didapatkan 15 pasien $(39,0 \%)$ sedangkan PSP ditemukan 7 pasien $(17,1 \%)$. Pada PSS ditemukan kasus tuberkulosis sebanyak 16 pasien dan kasus pneumotoraks hanya 2 pasien. Pada pneumotoraks traumatik ditemukan akibat KLL sebanyak 9 kasus dan akibat luka tusuk sebanyak 7 kasus.

\section{BAHASAN}

Pada penelitian ini ditemukan sebanyak 83 kasus pasien dengan klinis pneumotoraks yang melakukan pemeriksaan foto toraks di Bagian Radiologi RSUP Prof. Dr. R. D. Kandou Manado periode Januari 2015Agustus 2016 dan terdiagnosis secara radiologis sebanyak 41 kasus.

Temuan berdasarkan jenis kelamin didapatkan pasien pneumotoraks terbanyak yaitu pada laki-laki sebanyak 37 orang $(90,2 \%)$, sedangkan pada perempuan hanya ditemui sekitar 4 orang $(9,8 \%)$. Hasil penelitian ini sesuai dengan penelitian yang dilakukan oleh Surjanto et al. ${ }^{10}$ di RSUD Dr. Moewandi Surakarta tahun 2010 yaitu pasien pneumotoraks lebih banyak dijumpai pada jenis kelamin laki-laki $(64,10 \%)$ dari pada perempuan $(35,90 \%)$. Hal ini dikarenakan laki-laki mempunyai kebiasaan merokok yang merupakan salah satu faktor risiko spontan PSP. ${ }^{14}$

Pada temuan berdasarkan kelompok usia didapatkan kelompok usia terbanyak ialah $\geq 50$ tahun dengan jumlah 15 orang $(36,6 \%)$. Kelompok usia $\geq 50$ tahun dikaitkan dengan faktor biologi yaitu proses menua yang mengubah seorang dewasa sehat menjadi seorang yang rapuh dengan berkurangnya sebagian besar cadangan sistem fisiologis dan meningkatnya kerentanan terhadap berbagai penyakit seiring dengan bertambahnya usia. ${ }^{15}$

Temuan berdasarkan lokasi lesi hemitoraks pada 41 kasus pneumotoraks ditemukan lokasi lesi hemitoraks terbanyak pada lokasi paru kanan yaitu sekitar 22 orang $(53,7 \%)$ sedangkan paru kiri sekitar 19 orang (46,3\%). Hasil penelitian ini tidak jauh berbeda dengan penelitian yang dilakukan oleh Zeybek et al. ${ }^{14}$ di Turki yang mendapatkan dari 78 kasus pneumotoraks ditemukan lokasi lesi pada paru kanan $(59,5 \%)$ lebih banyak dari pada paru kiri $(39,3 \%)$. Hal ini kemungkinan 
berkaitan dengan bentuk anatomis bronkus kanan yang lebih vertikal, pendek, dan lebar dibandingkan dengan bronkus kiri sehingga benda asing yang terhirup lebih mudah tersangkut dalam percabangan bronkus kanan karena arahnya vertikal. ${ }^{16}$ Benda asing tersebut dapat berkaitan dengan agen infeksi penyebab penyakit paru yang mendasari terjadinya pneumotoraks contohnya tuberkulosis.

Pada penelitian ini didapatkan etiologi terbanyak dari pneumotoraks yaitu PSS (46,3\%). Pneumotoraks spontan sekunder timbul oleh karena penyakit paru yang mendasari. ${ }^{6}$ Tuberkulosis menjadi kasus penyebab PSS yang paling banyak dan ada juga oleh karena pneumonia. Penelitian ini sejalan dengan yang dilaporkan oleh Surjanto $^{10}$ di RSUD Dr. Moewandi Surakarta tahun 2010 bahwa PSS lebih banyak dijumpai pada pasien dan yang tersering ialah tuberkulosis $(46,15 \%)$, diikuti keganasan $(33,33 \%)$, pneumonia $(7,69 \%)$, dan PPOK (2,56\%). Hal ini terjadi mengingat kasus tuberkulosis masih tinggi di dunia. ${ }^{17}$

\section{SIMPULAN}

Dari hasil penelitian yang dilakukan di Bagian/SMF Radiologi RSUP Prof. R. D. Kandou Manado selama periode Januari 2015-Agustus 2016 dapat disimpulkan bahwa dari 83 kasus dengan klinis pneumotoraks yang terdiagnosis secara radiologis dengan gambaran pneumotoraks sebanyak 41 pasien. Mayoritas kasus ialah jenis kelamin laki-laki, kelompok usia $\geq 50$ tahun, distribusi lesi pada hemitoraks kanan, dengan etiologi pneumotoraks spontan sekunder.

\section{SARAN}

Disarankan dalam kelengkapan data rekam medik perlu diperhatikan untuk memperjelas data penyakit pasien khususnya pada hasil ekspertisi foto radiografi. Perlu dilakukan pencegahan terhadap faktor resiko untuk menurunkan angka kejadian penyakit pneumotoraks. Penelitian yang lebih lanjut tentang pneumotoraks sangat disarankan karena penelitian ini masih kurang dilakukan di Indonesia.

\section{DAFTAR PUSTAKA}

1. Ince A, Ozucelik DN, Avci A, Nizam O, Dogan H, Topal MA. Management of pneumothorax in emergency medicine departements: multicenter trial. Iran Red Cres Med J. 2013;15(12):1.

2. Light RW, Lee YCG. Pneumothorax, chylothorax, hemothorax and fibrothorax. In: Mason RJ, Broaddus VC, Murray JF, Nadel JA, editors. Murray and Nadel's Textbook of Respiratory Medicine (4th ed). Pennsylvania: Saunders, 2005; p. 1439.

3. Currie G, Alluri R, Christie GL, Legge JS. Pneumothorax: an update. Postgrad Med J. 2007;83:461.

4. Choi W. Pneumothorax. Tuberc Respir Dis. 2014;76:99.

5. Pearson FG, Deslauriers J, Ginsberg RJ, Hiebert CA, McKneally MF, Urschel HC. Spontaneous pneumothorax and pneumo-mediastinum. In: Beauchamp G, editors. Thoracic surgery. USA: Churchill Livingstone, 1995; p. 1037.

6. Sudoyo AW, Setiyohadi B, Alwi I, Simadibrata M, Setiati S. Pneumotoraks spontan. In: Hisyam B, Budiono E, editors. Buku Ajar Ilmu Penyakit Dalam (5th ed). Jakarta: Interna Publishing, 2009; p. 2339.

7. Melton LJ, Hepper NCG, Offord KP. Incidence of spontaneous pneumothorax in Olmsted Country, Minnesota:1950-1974. Am Rev Respir Dis. 1979;120(6):1379.

8. Parrish S, Browning RF, Turner F, Zarogoulidis K, Kougioumtzi I, Dryllis G, et al. The role for medical thoracoscopy in pneumothorax. Thorax Dis. 2014; 6(S4):383.

9. Weissberg D, Refaely Y. Pneumothorax: experience with 1.199 patients. Chest. 2000;117(5):1279.

10. Surjanto Y, Suradi, Raharjo AF. Tuberkulosis paru sebagai penyebab tertinggi kasus pneumotoraks di bangsal paru RSUD Dr Moewardi (RSDM) Surakarta tahun 2009 [Tesis]. Surakarta: SMF Pulmonologi RSUD Dr Moewardi; 2010.

11. Sadikot RT, Greene T, Meadows, A G Arnold. Recurrence of primary 
spontaneous pneumothorax. Thorax. 1997;52:808.

12. Rasad, Sjahriar. Radiologi Diagnostik (2nd ed). Jakarta: Balai Penerbit FK UI, 2005; p. 22,85,90.

13. Astowo P. Pneumotoraks. In: Swidarmoko B, Susanto AD, editors. Pulmonologi Intervensi dan Gawat Darurat Napas. Jakarta: Departemen Pulmonologi dan Ilmu Kedokteran Respirasi FK UI, 2010; p. 60.

14. Zeybek A, Kalemci S, Alma OG, Suzen A, Akgul M, Koc K. The effect of additional pleural procedures onto recurrence rates on the spontaneous pneumothorax surgery. Iran Red Cres Med J. 2013;15(2)136-41.

15. Pranarka K. Penerapan geriatrik kedokteran menuju usia lanjut yang sehat. Universa Medica. 2006;25(4):188.

16. Tortora G.J, Derrickson B. Principles of Anatomy and Physiology (13th ed). USA: John Wiley \& Sons, 2012; p. 92.

17. Kementrian Kesehatan Republik Indonesia. TBC masalah kesehatan dunia. 24 Maret 11 [cited 25 November 2016]. Available from: http://depkes.go.id/ article/print/1444/tbc-masalahkesehatan-dunia.html 